\title{
Osteoarthritis Induces Gender Related Changes in the Knee Range of Motion
}

\author{
Carmen Stătescu $^{1, *}$, Doru Stoica ${ }^{2,}$, Bogdan-Ion Gavrilă ${ }^{3}$, Magdalena-Rodica Trăistaru ${ }^{4}$ and Tudor-Adrian Bălșeanu ${ }^{1}$ \\ 1 University of Medicine and Pharmacy of Craiova, Faculty of Medicine, Physiology Department, Craiova, \\ Romania; statescu.carmen@gmail.com ; adibalseanu@yahoo.com \\ 2 University of Craiova, Faculty of Physical Education and Sport, Craiova, Romania; dorustoicaa@gmail.com \\ ${ }^{3}$ Carol Davila University of Medicine and Pharmacy, Bucharest, Faculty of Medicine, Bucharest, Romania; \\ bogdang135@yahoo.com \\ ${ }^{4}$ University of Medicine and Pharmacy of Craiova, Faculty of midwives and nursing, Craiova, Romania; \\ rodicatraistru@hotmail.com \\ * Correspondent author: statescu.carmen@gmail.com (C.S.); dorustoicaa@gmail.com (D.S.)
}

\begin{abstract}
In time, osteoarthritis (OA) generates the misalignment of the affected joint structures. However, due to the nature of bipedal gait, $\mathrm{OA}$ in the lower limb can also cause pathological gait patterns, which can generate instability and falls, with great consequence, especially in the aged population. With goniometry used to evaluate the range of motion of joints (ROM), we wanted to evaluate how gender impacts gait dynamics in OA patients. For this study we have compared 106 OA patients (male=32, female=74) to age matched controls. All participants had their right leg as dominant. Video recording of normal gait was analysed with a digital goniometry tool phone application, and the knee's ROM was measured in midstance and midswing of the gait. During midstance, significant extension and flexion of the knee excursion have been observed in both males and females. During midswing, knee OA presents more differences, whereas subjects with hip and knee OA present changes on the dominant knee. Midstance changes suggest that the knee's joint degenerative changes can be linked to hip OA secondary changes. Midswing changes in lower limb OA suggest a connection to the activities of daily life. Gender differences generated by OA must furthermore be studied in both lower limbs so that the best therapeutic approach can be chosen.
\end{abstract}

Keywords: angles app, goniometry, range of motion, assessment, telemedicine, joint examination.

\section{Introduction}

Osteoarthritis (OA) affects millions in Europe alone [1,2]. With OA impacting the alignment of bone and joint structure it has the potential to generate disability either by itself or as a consequence of the higher falling rate of OA patients [3-5]. Ultimately, OA affects mobility and, in time, the gait of patients [6-10] making the correct diagnosis and treatment essential in order to ensure an active life for OA patients. The classical approach in evaluating the gravity of $\mathrm{OA}$ is to perform a goniometry exam. This generates range of motion (ROM) information that is obtained from a static measurement [11-14]. Even though goniometry is a routine clinical examination, being largely subjective leaves room for small mistakes from one examination to another, or between different evaluating 
physicians. To provide a more reliable and accurate measurement, automatic software has been used to standardize these measurements. To simplify goniometry, physicians can now use smartphone technology and applications that are able to provide cheap, objective and detailed goniometry evaluation [15-21].

With processes in OA starting from cell stress and degradations [1,2], the clinical detection of gait disturbances can be difficult $[8,10,22]$. Thus, automatic gait analysis can prove beneficial for different types of patients $[7,8,23,24]$. In state-of-the-art gait labs, threedimensional motion analysis can be obtained. This can include, but is not restricted to plantar pressure plates and electromyography analysis [25-27]. Unfortunately, the running cost and sheer size of such labs make it impractical to have them outside regional hospitals $[15,28-32]$. This is why video assisted goniometry applications look like a viable alternative, proving their validity versus both mechanical goniometer and a two-dimensional motion analysis software used in research settings for static and gait analysis [7]. As such, reliable goniometry is made simpler. Furthermore, as most of this automated software can separately analyse the two major gait stages: stance (subdivided into: loading response, midstance, terminal stance) and swing (subdivided into: initial swing, midswing and terminal swing) [6,33], such applications have great potential in clinical use, especially in rehabilitation labs.

With two independent processes taking place at the same time: age related changes in the knee's ROM, during midstance [34] and OA affecting stability [10,34,35], early correction of midstance posture becomes essential to prevent falls in older patients suffering from OA of the lower leg joints $[4,5,37-40]$. If left untreated, OA can lead to great disability and even death in elderly, secondary to fractures from falling [5,41-43]. Furthermore, as some gender-related changes exist in lower limb alignment and ROM in elderly [44], in sportsmen [45,46], or even in simple single-leg drop jumps [47], we wanted to investigate if gender plays a role in the midstance and midswing of knee's ROM in patients suffering from OA of the hip, knee or both.

\section{Materials and Methods}

\section{Study design}

For this study we have initially enrolled 124 patients (November 2019 to March 2021) suffering from lower limb OA. At the start, no clinical or functional difference between left and right was observed. The inclusion criteria were hip and/or knee pain, Kellgren and Lawrence radiological assessment of lower limb OA, stages 1-3. The exclusion criteria were the inability of walking without the help of an assistive device as a cane or walking frame due to stage 4 osteoarthritis (hip, knee or hip and knee), history of joint replacement, stroke or neurological lesions, history of lumbar herniated disc, or severe balance problems.

Depending on the localization of the OA lesion, the remaining 106 subjects (74 females and 32 males) have been divided into 3 OA groups: primary hip bilateral arthritis (42), primary knee bilateral arthritis (25), primary hip and knee bilateral OA (39) and a control group (30), all having the right lower limb as a dominant limb. All subjects in the study were volunteers. 
All participants in the study have given their Informed Consent according to the principles outlined in the Declaration of Helsinki. Additionally, the study was approved by the Ethics and Academic and Scientific Deontology Committee of the University of Medicine and Pharmacy of Craiova (no. 111/21.10.2019).

\section{Video-assisted goniometry measurements}

To determine the knee's ROM, patients were recorded while walking at their normal gait speed for 3 meters. The recording was made during a second gait cycle, in a sagittal plane and the left and right sides were separately recorded. We used a fixed camera, placed $1 \mathrm{~m}$ from the ground.

The videos were uploaded into Angles video goniometry App (a smartphone app funded by Duquesne University, Pennsylvania, USA, generated for the improvement of motor skills in paediatric physical therapy [48]) [16]. Within the 3-meter distance, the patients reach the midstance and midswing position 2-3 times. The measure was made on the second midstance and midswing, as the first one was discarded as being too close to the start position and the $3^{\text {rd }}$ was usually towards the end of the distance and the gait was visible distorted by the patients. Using the second midstance and midswing of the gait, the ROM measurement was done manually marking the great trochanter, lateral condyle and lateral ankle generating the posterior angle of the knee.

After data acquisition, a two-way ANOVA test (Šídák's multiple comparisons test) was performed. The statistical significance was set at $\mathrm{P}<0.05$. All figures display mean value and standard deviation (SD), and the statistical significance is displayed as follows: $*: \mathrm{P}<=0.05,{ }^{* *}: \mathrm{P}<=0.01,{ }^{* * *}: \mathrm{P}<=0.001$ and ${ }^{* * * *}: \mathrm{P}<=0.0001$.

\section{Results}

\subsection{The knee's ROM changes based on the gender during midstance of $O A$ patients}

During midstance, the knee's ROM in men and women changes depending on the joint affected by OA and the side of the lesion. As such, in men suffering from left hip OA, the ROM of the knee increases compared to controls $\left(170.5^{\circ}\right.$ compared to $162.8^{\circ}, \mathrm{P}=0.0117$ ) (Figure 1B), generating a higher knee extension. No difference can be seen in men suffering from hip OA in the right leg (Figure 1A). In contrast, female subjects suffering from hip OA of the dominant leg, adapt by increasing the knee's ROM compared to controls $\left(159.740^{\circ}\right.$ in control groups compared to $\left.168.758^{\circ}, \mathrm{P}<0.0001\right)$, while women with hip OA have no impact in the knee's ROM of the non-dominant lower limb $\left(160.793^{\circ}\right.$ compared to $164.234^{\circ}, \mathrm{P}>0.05$ ) (Figure 1B).

Interestingly, the only difference we found when analysing the knee's ROM in patients with knee OA, in midstance, was in the dominant leg of males $\left(166.057^{\circ}\right.$ compared to $156.58^{\circ}, \mathrm{P}<0.0001$ ) (Figure $1 \mathrm{~F}$ ), with females maintaining a close to normal ROM even in the presence of OA (Figure 1E).

When investigating the $\mathrm{ROM}$ in patients with $\mathrm{OA}$ in both hip and knee, the difference observed was basically a summation of hip and knee changes seen in the individual patients' groups. As such, the non-dominant leg was affected in males with a higher knee excursion than the control $\left(162.843^{\circ}\right.$ in controls compared to $170.677^{\circ}$ in OA patients, $\mathrm{P}=0.0140$ ) (Figure $1 \mathrm{C}$ ), with both females and males exhibiting adaptive changes 
in the knee ROM of the dominant leg (control male group $166.057^{\circ}$ compared to $160.547^{\circ}$, control female group $159.740^{\circ}$ compared to hip and knee female group $164.245^{\circ}$ ) (Figure 1D).
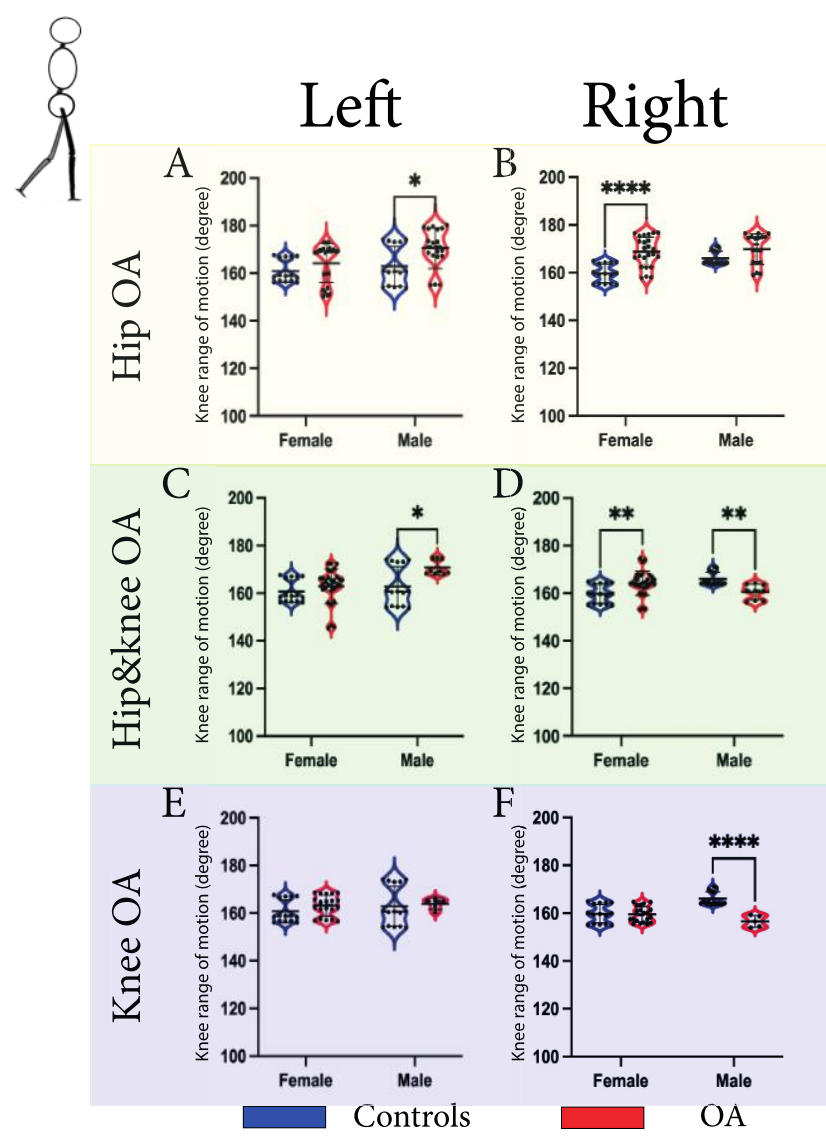

Figure 1. Knee's ROM in patients suffering from lower limb joint $O A$ during midstance. While hip $O A$ increases the knee's ROM of the left leg in men $(A)$, in females this can only be noticed on the right leg $(B)$. In contrast with hip $O A$, knee $O A$ only affects the right knee's $R O M$ during midstance in men and not women (D), that suffer no measurable consequences in both legs (C). In males suffering from both hip and knee $O A$ both knees left $(E)$ and right (F) present significant differences, while in women with hip and knee $O A$ results were underlined only in the right knee's ROM (F). (The statistical significance is displayed as follows: *: $\mathrm{P}<=0.05,{ }^{* *}: \mathrm{P}<=0.01,{ }^{* * *}$ : $\mathrm{P}<=0.001$ and $\left.{ }^{* * * *}: \mathrm{P}<=0.0001\right)$

\subsection{The midswing of OA patients generates less gender specific changes in the knee's ROM}

During midswing, female groups present the most interesting changes, regardless of the joint where the OA lesion was noted (Figure 2B, D and F). In all these cases, we observed an increase in the knee ROM of women with OA. In hip OA groups the only gender specific change of knee ROM was in the dominant leg of women with an increase of the knee's $\operatorname{ROM}\left(137.967^{\circ}\right.$ compared to $\left.147.325^{\circ}, \mathrm{P}=0.0020\right)$ (Figure 2B), generating a knee extension.

Interestingly, the non-dominant knee ROM decreased for both males and females with knee OA $\left(140.583^{\circ}\right.$ in control group comparing to $135.997^{\circ}$ in females with knee OA, 
$\mathrm{P}=0.0306$ and $148.173^{\circ}$ in control compared to $131.570^{\circ}$ in males with knee $\mathrm{OA}, \mathrm{P}<0.0001$ ) (Figure 2E), while, on the dominant side, only women presented significant increasing differences $\left(137.967^{\circ}\right.$ compared to $\left.151.928^{\circ}, \mathrm{P}=0.0024\right)$ (Figure $2 \mathrm{~F}$ ), exhibiting a knee extension, as opposed to the non-dominant side.

In the dominant leg of patients with both hip and knee OA, the knee's ROM was different both for males and females ( $137.967^{\circ}$ compared to $144.208^{\circ}, \mathrm{P}=0.0006$ for females and $150.280^{\circ}$ compared to $141.423^{\circ}, \mathrm{P}=0.0003$ for males) (Figure 2D). However, the nature of change is different between genders. If for women the ROM has decreasing values comparing to the control group, for males the ROM increases (Figure 2D), while on the non-dominant side, the values were not significant (Figure $2 \mathrm{C}$ ).

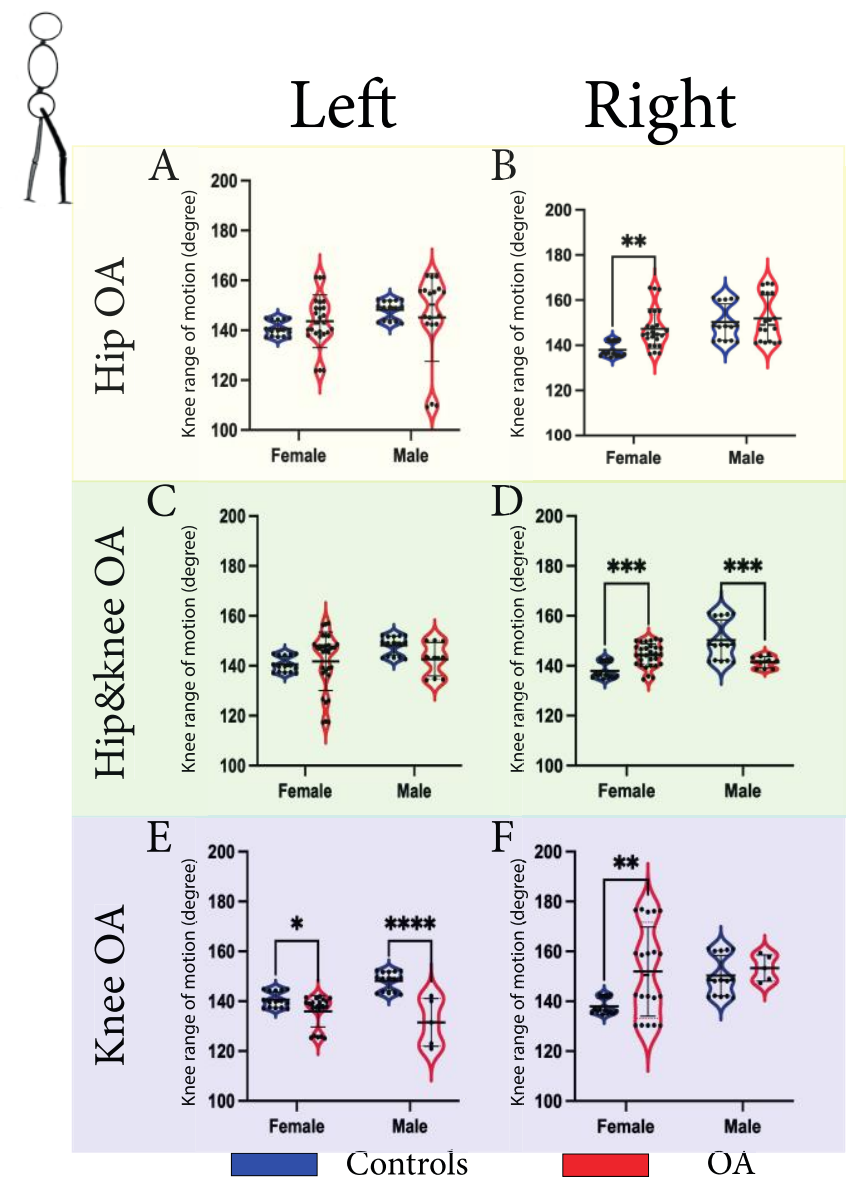

Figure 2. Knee's ROM in patients suffering from lower limb joint $O A$ during midswing. While hip OA present no significant results the knee's ROM of the left $(A)$ nor right $(B)$ leg in men, females only exhibit present significant results in the right knee's ROM group with hip OA (B). In contrast, knee OA only affects the right knee's ROM during midswing in men and women (F), but females nor males suffer measurable consequences on the left side (E). In males and females suffering from both hip and knee OA the left knee ROM (C) presents no significant results whereas on the right knee underlines important differences in both genders $(D)$. (The statistical significance is displayed as follows: *: $\mathrm{P}<=0.05,{ }^{* *}: \mathrm{P}<=0.01,{ }^{* * *}: \mathrm{P}<=0.001$ and $\left.{ }^{* * *}: \mathrm{P}<=0.0001\right)$ 


\section{Discussion}

In this study we were able to show, using objective goniometry measurements, differences between the knee's ROM of men and women suffering from lower limb OA, confirming our initial hypothesis. This calls for the need of a detailed investigation of such patients so that the best therapeutic option can be correctly implemented furthermore.

With the progression of degenerative processes accompanying OA, gait adaptation is inevitable [49-53]. While the speed of gait is visible impacted [54], the ROM of the knee is less investigated, but left uncorrected it increases the risk of instability and falls $[41,43]$. With OA affecting gait in different ways, some pathological gait cycles can be observed starting with a simple antalgic or coxalgic gait, all the way to Trendelenburg gait $[22,27,44,55,56]$. Although, such changes are frequently described in literature, OA adaptive changes between OA genders are not that well investigated, although differences between normal gait are also frequently cited [44-47].

With more and more people needing hip or knee replacement surgery [52,57], the prevention of these late stages through correct physical therapy seems like a cheaper and more beneficial approach for OA patients [58-60]. With midstance being an important factor of stability in gait, of note is the presence of changes in the knee's ROM in patients with hip OA, with females being susceptible to dominant leg changes, while males to nondominant ones (Figure 1A and B). It is unclear if our observations are secondary due to hip joint's abnormalities [61], however, their existence needs to be closely investigated and corrected.

During the same gait time point, only the dominant leg of males' patients suffering from knee OA seem to suffer changes in the knee ROM (Figure 1F). To continue, male subjects with $\mathrm{OA}$ affecting both hip and knee joints tend to have a more flexed dominant knee during midstance (Figure $1 \mathrm{E}$ and $\mathrm{F}$ ) with similar findings in knee's ROM in literature $[62,63]$. A more interesting fact to be furthermore researched in these patients suffering from lower limb OA with knee abnormalities comparable to our results is the importance of BMI in one's OA formation. It is important to underline since it was shown that men that lose weight tend to have a decreased opportunity of developing OA in their elderly years, but not so many findings emphasize which are the differences between the dominant and non-dominant lower limbs [64-66]. Females with hip OA (with or without knee OA) present important changes on the dominant limb, even though in literature it has been tried to see whether the dominance of the limb generates $\mathrm{OA}$ joint degenerations, or it is actually the disease that may cause differences between limbs, but a longitudinal examination needs approaching as well [67].

During the midswing stage of gait, the only two gender difference are indicated in female in the dominant leg (Figure $2 \mathrm{~B}$ and $\mathrm{D}$ ). It remains unclear whether these alterations are solely caused by the joint degeneration and the subsequent gait adaptation, or the differences can be caused by other factors like pregnancy [68], or even social dresscodes that impacts females gait $[61,69]$. With midswing changes having been reported only in female and not male dancers [70], we were able to show that females suffer knee ROM changes only in the dominant lower leg (Figure $2 \mathrm{~B}$ and D). Nevertheless, it leads us to 
speculate that lower limb OA alterations during midstance can be linked to the activities of daily life, without minimizing the need to correct it in these patients.

Not many data is exhibited differentiating midstance or midswing phases in knee's ROM in females with knee OA (Figure 2E and F) even though other studies exhibited a decrease knee ROM angles across the gait cycle [45,71,72]. Different results presented between midstance and midswing phases of this study can be caused by important variances in the study design and methods used.

Our observations made on men with hip and knee OA and men with knee OA (Figure $2 \mathrm{D}$ and E) may lead us to think that since the hamstring muscles are biarticular muscles [73] they cannot control the subject's extension [74] in both joints without causing any pain. Hence a reduction of the pain will be present through a modified knee angle during midswing [75].

Given the fact that the results are significant compared to the control group, it means that $\mathrm{OA}$ acts differently in both women and men, but the outcome is similar. Be that as it may, current research acknowledges its limitations. Gender related changes in OA must also be backed by BMI studies along with OA, beside female-male further comparisons taking activities of daily life into consideration.

\section{Conclusions}

Bipedal gait consists in being one of the most important function of humans, alongside with speech abilities. Goniometry has been and still is one of the best methods of diagnostics used in lower limb pathologies. Even though this method has its limitations, our findings have, overall, comparable outcomes with previous studies. Gait disorders increase with age; hence, it is highly important to know what roles gender play during the stages of midstance and midswing of the knee in patients with hip OA, knee OA, or hip and knee OA. The causality of OA remains not completely known, but correlations with patient's history and activities of daily living give us important insight so that a complete personalized rehabilitation program through exercises can be initiated as a cautious measure and prevent arthroplasty.

Author Contributions: conceptualization: Carmen Stătescu, methodology: Doru Stoica; software: Bogdan-Ion Gavrilă; validation: Doru Stoica and Bogdan-Ion Gavrilă; formal analysis: Carmen Stătescu; investigation: Carmen Stătescu; resources: Rodica Trăistaru and Tudor-Adrian Bălșeanu; data curation: Bogdan-Ion Gavrilă.; writing-original draft preparation: Carmen Stătescu.; writing - review and editing: Carmen Stătescu, Rodica Trăistaru and Tudor-Adrian Bălșeanu, visualization: Carmen Stătescu; supervision: Rodica Trăistaru and Tudor-Adrian Bălșeanu; project administration: Rodica Trăistaru and Tudor-Adrian Bălșeanu; funding acquisition: not applicable. All authors have read and agreed to the published version of the manuscript.

Funding: This research received no external funding.

Institutional Review Board Statement: An ethical approval of the research project has been released by the Committee of Ethics and Academic and Scientific Deontology (Institutional Review Board) of the University of Medicine and Pharmacy of Craiova (no. 111/21.10.2019). 
Informed Consent Statement: Informed consent was obtained from all subjects involved in the study.

Conflicts of Interest: The authors declare no conflict of interest.

\section{References}

1. Conaghan, P.G.; Kloppenburg, M.; Schett, G.; Bijlsma, J.W.J.; EULAR osteoarthritis ad hoc committee Osteoarthritis Research Priorities: A Report from a EULAR Ad Hoc Expert Committee. Ann Rheum Dis 2014, 73, 14421445, doi:10.1136/annrheumdis-2013-204660.

2. Standardization of Osteoarthritis Definitions Available online: https://oarsi.org/research/standardizationosteoarthritis-definitions (accessed on 22 February 2021).

3. Mat, S.; Ng, C.T.; Tan, P.J.; Ramli, N.; Fadzli, F.; Rozalli, F.I.; Mazlan, M.; Hill, K.D.; Tan, M.P. Effect of Modified Otago Exercises on Postural Balance, Fear of Falling, and Fall Risk in Older Fallers With Knee Osteoarthritis and Impaired Gait and Balance: A Secondary Analysis. PM R 2018, 10, 254-262, doi:10.1016/j.pmrj.2017.08.405.

4. Balance, Gait, and Falls, Volume 159 - 1st Edition Available online: https://www.elsevier.com/books/balance-gaitand-falls/day/978-0-444-63916-5 (accessed on 22 February 2021).

5. Svoboda, Z.; Bizovska, L.; Janura, M.; Kubonova, E.; Janurova, K.; Vuillerme, N. Variability of Spatial Temporal Gait Parameters and Center of Pressure Displacements during Gait in Elderly Fallers and Nonfallers: A 6-Month Prospective Study. PLoS One 2017, 12, doi:10.1371/journal.pone.0171997.

6. Cruz-Jimenez, M. Normal Changes in Gait and Mobility Problems in the Elderly. Physical Medicine and Rehabilitation Clinics of North America 2017, 28, 713-725, doi:10.1016/j.pmr.2017.06.005.

7. Zeng, X.; Ma, L.; Lin, Z.; Huang, W.; Huang, Z.; Zhang, Y.; Mao, C. Relationship between Kellgren-Lawrence Score and 3D Kinematic Gait Analysis of Patients with Medial Knee Osteoarthritis Using a New Gait System. Sci Rep 2017, 7, doi:10.1038/s41598-017-04390-5.

8. Mündermann, A.; Dyrby, C.O.; Andriacchi, T.P. Secondary Gait Changes in Patients with Medial Compartment Knee Osteoarthritis: Increased Load at the Ankle, Knee, and Hip during Walking. Arthritis Rheum 2005, 52, 2835-2844, doi:10.1002/art.21262.

9. Buckup, K. Clinical Tests for the Musculoskeletal System: Examinations - Signs - Phenomena. undefined 2008.

10. Knee Joint Instability in Knee Osteoarthritis: Effect on Gait Biomechanics and Motor Control - Osteoarthritis and Cartilage Available online: https://www.oarsijournal.com/article/S1063-4584(19)30230-4/fulltext (accessed on 13 June 2021).

11. Gajdosik, R.L.; Bohannon, R.W. Clinical Measurement of Range of Motion. Review of Goniometry Emphasizing Reliability and Validity. Phys Ther 1987, 67, 1867-1872, doi:10.1093/ptj/67.12.1867.

12. Hancock, G.E.; Hepworth, T.; Wembridge, K. Accuracy and Reliability of Knee Goniometry Methods. J Exp Orthop 2018, 5, 46, doi:10.1186/s40634-018-0161-5.

13. Gandbhir, V.N.; Cunha, B. Goniometer. In StatPearls; StatPearls Publishing: Treasure Island (FL), 2021.

14. Waddell, B.S.; Duplantier, N.L.; Luo, Q.; Meyer, M.S.; Duncan, S.F.M. Smartphone-Based Goniometry Accuracy in Clinical Scenarios. J Surg Orthop Adv 2017, 26, 223-226.

15. Finkbiner, M.J.; Gaina, K.M.; McRandall, M.C.; Wolf, M.M.; Pardo, V.M.; Reid, K.; Adams, B.; Galen, S.S. Video Movement Analysis Using Smartphones (ViMAS): A Pilot Study. J Vis Exp 2017, doi:10.3791/54659.

16. Cunha, A.B.; Babik, I.; Harbourne, R.; Cochran, N.J.; Stankus, J.; Szucs, K.; Lobo, M.A. Assessing the Validity and Reliability of a New Video Goniometer App for Measuring Joint Angles in Adults and Children. Arch Phys Med Rehabil 2020, 101, 275-282, doi:10.1016/j.apmr.2019.07.008. 
17. Mousavi, S.H.; Hijmans, J.M.; Moeini, F.; Rajabi, R.; Ferber, R.; van der Worp, H.; Zwerver, J. Validity and Reliability of a Smartphone Motion Analysis App for Lower Limb Kinematics during Treadmill Running. Phys Ther Sport 2020, 43, 27-35, doi:10.1016/j.ptsp.2020.02.003.

18. Lee, S.; Walker, R.M.; Kim, Y.; Lee, H. Measurement of Human Walking Movements by Using a Mobile Health App: Motion Sensor Data Analysis. JMIR Mhealth Uhealth 2021, 9, e24194, doi:10.2196/24194.

19. Milanese, S.; Gordon, S.; Buettner, P.; Flavell, C.; Ruston, S.; Coe, D.; O'Sullivan, W.; McCormack, S. Reliability and Concurrent Validity of Knee Angle Measurement: Smart Phone App versus Universal Goniometer Used by Experienced and Novice Clinicians. Man Ther 2014, 19, 569-574, doi:10.1016/j.math.2014.05.009.

20. King, D.L.; Belyea, B.C. Reliability of Using a Handheld Tablet and Application to Measure Lower-Extremity Alignment Angles. J Sport Rehabil 2015, T24, doi:10.1123/jsr.2014-0195.

21. Jones, A.; Sealey, R.; Crowe, M.; Gordon, S. Concurrent Validity and Reliability of the Simple Goniometer IPhone App Compared with the Universal Goniometer. Physiother Theory Pract 2014, 30, 512-516, doi:10.3109/09593985.2014.900835.

22. Reininga, I.H.; Stevens, M.; Wagenmakers, R.; Bulstra, S.K.; Groothoff, J.W.; Zijlstra, W. Subjects with Hip Osteoarthritis Show Distinctive Patterns of Trunk Movements during Gait-a Body-Fixed-Sensor Based Analysis. J Neuroeng Rehabil 2012, 9, 3, doi:10.1186/1743-0003-9-3.

23. Fransen, M.; Crosbie, J.; Edmonds, J. Reliability of Gait Measurements in People with Osteoarthritis of the Knee. Phys Ther 1997, 77, 944-953, doi:10.1093/ptj/77.9.944.

24. Ro, D.H.; Lee, J.; Lee, J.; Park, J.-Y.; Han, H.-S.; Lee, M.C. Effects of Knee Osteoarthritis on Hip and Ankle Gait Mechanics. Advances in Orthopedics 2019, 2019, 1-6, doi:10.1155/2019/9757369.

25. Kim, J.J.; Cho, H.; Park, Y.; Jang, J.; Kim, J.W.; Ryu, J.S. Biomechanical Influences of Gait Patterns on Knee Joint: Kinematic \& EMG Analysis. PLoS One 2020, 15, doi:10.1371/journal.pone.0233593.

26. Aliberti, S.; de S.X. Costa, M.; de Campos Passaro, A.; Arnone, A.C.; Hirata, R.; Sacco, I.C.N. Influence of Patellofemoral Pain Syndrome on Plantar Pressure in the Foot Rollover Process during Gait. Clinics (Sao Paulo) 2011, 66, 367-372, doi:10.1590/S1807-59322011000300001.

27. Deluzio, K.J.; Astephen, J.L. Biomechanical Features of Gait Waveform Data Associated with Knee Osteoarthritis: An Application of Principal Component Analysis. Gait Posture 2007, 25, 86-93, doi:10.1016/j.gaitpost.2006.01.007.

28. Milani, P.; Coccetta, C.A.; Rabini, A.; Sciarra, T.; Massazza, G.; Ferriero, G. Mobile Smartphone Applications for Body Position Measurement in Rehabilitation: A Review of Goniometric Tools. PM R 2014, 6, 1038-1043, doi:10.1016/j.pmrj.2014.05.003.

29. Milani, P.; Coccetta, C.; Rabini, A.; Sciarra, T.; Massazza, G.; Ferriero, G. A Review of Mobile Smartphone Applications for Body Position Measurement in Rehabilitation: A Focus on Goniometric Tools. PM $\mathcal{E}$ : the journal of injury, function, and rehabilitation 2014, 6, doi:10.1016/j.pmrj.2014.05.003.

30. Keogh, J.W.L.; Cox, A.; Anderson, S.; Liew, B.; Olsen, A.; Schram, B.; Furness, J. Reliability and Validity of Clinically Accessible Smartphone Applications to Measure Joint Range of Motion: A Systematic Review. PLoS One 2019, 14, e0215806, doi:10.1371/journal.pone.0215806.

31. Vercelli, S.; Sartorio, F.; Bravini, E.; Ferriero, G. DrGoniometer: A Reliable Smartphone App for Joint Angle Measurement. British journal of sports medicine 2017, 1703-1704, doi:10.1136/bjsports-2016-096727.

32. Ornetti, P.; Maillefert, J.-F.; Laroche, D.; Morisset, C.; Dougados, M.; Gossec, L. Gait Analysis as a Quantifiable Outcome Measure in Hip or Knee Osteoarthritis: A Systematic Review. Joint Bone Spine 2010, 77, 421-425, doi:10.1016/j.jbspin.2009.12.009.

33. Kuo, A.D.; Donelan, J.M. Dynamic Principles of Gait and Their Clinical Implications. Physical Therapy 2010, 90, 157-174, doi:10.2522/ptj.20090125. 
34. Oberg, T.; Karsznia, A.; Oberg, K. Joint Angle Parameters in Gait: Reference Data for Normal Subjects, 10-79 Years of Age. J Rehabil Res Dev 1994, 31, 199-213.

35. Farrokhi, S.; O'Connell, M.; Gil, A.B.; Sparto, P.J.; Fitzgerald, G.K. Altered Gait Characteristics in Individuals with Knee Osteoarthritis and Self-Reported Knee Instability. J Orthop Sports Phys Ther 2015, 45, 351-359, doi:10.2519/jospt.2015.5540.

36. Levin, S. Closed Kinematic Chain Mechanisms Comprise the Fundamental Mechanics of Biologic Movement and Stability. 2013.

37. Binotto, M.A.; Lenardt, M.H.; Rodríguez-Martínez, M.D.C. Physical frailty and gait speed in community elderly: a systematic review. Rev Esc Enferm USP 2018, 52, e03392, doi:10.1590/S1980-220X2017028703392.

38. Cheung, C.; Wyman, J.F.; Bronas, U.; McCarthy, T.; Rudser, K.; Mathiason, M.A. Managing Knee Osteoarthritis with Yoga or Aerobic/Strengthening Exercise Programs in Older Adults: A Pilot Randomized Controlled Trial. Rheumatol Int 2017, 37, 389-398, doi:10.1007/s00296-016-3620-2.

39. Hale, L.A.; Waters, D.; Herbison, P. A Randomized Controlled Trial to Investigate the Effects of Water-Based Exercise to Improve Falls Risk and Physical Function in Older Adults with Lower-Extremity Osteoarthritis. Arch Phys Med Rehabil 2012, 93, 27-34, doi:10.1016/j.apmr.2011.08.004.

40. Mat, S.; Tan, M.P.; Kamaruzzaman, S.B.; Ng, C.T. Physical Therapies for Improving Balance and Reducing Falls Risk in Osteoarthritis of the Knee: A Systematic Review. Age Ageing 2015, 44, 16-24, doi:10.1093/ageing/afu112.

41. Manlapaz, D.G.; Sole, G.; Jayakaran, P.; Chapple, C.M. Risk Factors for Falls in Adults with Knee Osteoarthritis: A Systematic Review. PM R 2019, 11, 745-757, doi:10.1002/pmrj.12066.

42. Kannus, P.; Parkkari, J.; Koskinen, S.; Niemi, S.; Palvanen, M.; Järvinen, M.; Vuori, I. Fall-Induced Injuries and Deaths among Older Adults. JAMA 1999, 281, 1895-1899, doi:10.1001/jama.281.20.1895.

43. Ikutomo, H.; Nagai, K.; Tagomori, K.; Miura, N.; Nakagawa, N.; Masuhara, K. Incidence and Risk Factors for Falls in Women With End-Stage Hip Osteoarthritis. J Geriatr Phys Ther 2019, 42, 161-166, doi:10.1519/JPT.0000000000000156.

44. Laufer, Y. Age- and Gender-Related Changes in the Temporal-Spatial Characteristics of Forwards and Backwards Gaits. Physiother Res Int 2003, 8, 131-142, doi:10.1002/pri.281.

45. Mitani, Y. Gender-Related Differences in Lower Limb Alignment, Range of Joint Motion, and the Incidence of Sports Injuries in Japanese University Athletes. J Phys Ther Sci 2017, 29, 12-15, doi:10.1589/jpts.29.12.

46. Howell, D.R.; Stracciolini, A.; Geminiani, E.; Meehan, W.P. Dual-Task Gait Differences in Female and Male Adolescents Following Sport-Related Concussion. Gait Posture 2017, 54, 284-289, doi:10.1016/j.gaitpost.2017.03.034.

47. Aizawa, J.; Hirohata, K.; Ohji, S.; Ohmi, T.; Yagishita, K. Limb-Dominance and Gender Differences in the Ground Reaction Force during Single-Leg Lateral Jump-Landings. J Phys Ther Sci 2018, 30, 387-392, doi:10.1589/jpts.30.387.

48. Currently Funded Projects Available online: https:/duq.edu/academics/schools/health-sciences/outreach-andresearch-facilities/infant-development-lab/currently-funded-projects- (accessed on 9 July 2021).

49. Mine, T.; Kajino, M.; Sato, J.; Itou, S.; Ihara, K.; Kawamura, H.; Kuriyama, R.; Tominaga, Y. Gait Oscillation Analysis during Gait and Stair-Stepping in Elder Patients with Knee Osteoarthritis. J Orthop Surg Res 2019, 14, 21, doi:10.1186/s13018-019-1064-6.

50. Iijima, H.; Shimoura, K.; Ono, T.; Aoyama, T.; Takahashi, M. Proximal Gait Adaptations in Individuals with Knee Osteoarthritis: A Systematic Review and Meta-Analysis. J Biomech 2019, 87, 127-141, doi:10.1016/j.jbiomech.2019.02.027. 51. Duffell, L.D.; Jordan, S.J.; Cobb, J.P.; McGregor, A.H. Gait Adaptations with Aging in Healthy Participants and People with Knee-Joint Osteoarthritis. Gait Posture 2017, 57, 246-251, doi:10.1016/j.gaitpost.2017.06.015.

52. Elkarif, V.; Kandel, L.; Rand, D.; Schwartz, I.; Greenberg, A.; Portnoy, S. Kinematics Following Gait Perturbation in Adults with Knee Osteoarthritis: Scheduled versus Not Scheduled for Knee Arthroplasty. Gait Posture 2020, 81, 144152, doi:10.1016/j.gaitpost.2020.07.021. 
53. Alkjaer, T.; Raffalt, P.C.; Dalsgaard, H.; Simonsen, E.B.; Petersen, N.C.; Bliddal, H.; Henriksen, M. Gait Variability and Motor Control in People with Knee Osteoarthritis. Gait Posture 2015, 42, 479-484, doi:10.1016/j.gaitpost.2015.07.063. 54. Kozakai, R.; Tsuzuku, S.; Yabe, K.; Ando, F.; Niino, N.; Shimokata, H. Age-Related Changes in Gait Velocity and Leg Extension Power in Middle-Aged and Elderly People. J Epidemiol 2000, 10, S77-81, doi:10.2188/jea.10.1sup_77.

55. Allison, K.; Hall, M.; Hodges, P.W.; Wrigley, T.V.; Vicenzino, B.; Pua, Y.-H.; Metcalf, B.; Grimaldi, A.; Bennell, K.L. Gluteal Tendinopathy and Hip Osteoarthritis: Different Pathologies, Different Hip Biomechanics. Gait Posture 2018, 61, 459-465, doi:10.1016/j.gaitpost.2018.02.011.

56. Petrofsky, J.S. Microprocessor-Based Gait Analysis System to Retrain Trendelenburg Gait. Med Biol Eng Comput 2001, 39, 140-143, doi:10.1007/BF02345278.

57. Bączkowicz, D.; Skiba, G.; Czerner, M.; Majorczyk, E. Gait and Functional Status Analysis before and after Total Knee Arthroplasty. Knee 2018, 25, 888-896, doi:10.1016/j.knee.2018.06.004.

58. de Matos Brunelli Braghin, R.; Libardi, E.C.; Junqueira, C.; Rodrigues, N.C.; Nogueira-Barbosa, M.H.; Renno, A.C.M.; Carvalho de Abreu, D.C. The Effect of Low-Level Laser Therapy and Physical Exercise on Pain, Stiffness, Function, and Spatiotemporal Gait Variables in Subjects with Bilateral Knee Osteoarthritis: A Blind Randomized Clinical Trial. Disabil Rehabil 2019, 41, 3165-3172, doi:10.1080/09638288.2018.1493160.

59. Jaczewska-Bogacka, J.; Stolarczyk, A. Improvement in Gait Pattern After Knee Arthroplasty Followed by Proprioceptive Neuromuscular Facilitation Physiotherapy. Adv Exp Med Biol 2018, 1096, 1-9, doi:10.1007/5584_2018_187. 60. Rahmann, A.E.; Brauer, S.G.; Nitz, J.C. A Specific Inpatient Aquatic Physiotherapy Program Improves Strength after Total Hip or Knee Replacement Surgery: A Randomized Controlled Trial. Arch Phys Med Rehabil 2009, 90, 745-755, doi:10.1016/j.apmr.2008.12.011.

61. Eitzen, I.; Fernandes, L.; Nordsletten, L.; Risberg, M.A. Sagittal Plane Gait Characteristics in Hip Osteoarthritis Patients with Mild to Moderate Symptoms Compared to Healthy Controls: A Cross-Sectional Study. BMC Musculoskelet Disord 2012, 13, 258, doi:10.1186/1471-2474-13-258.

62. Astephen, J.L.; Deluzio, K.J.; Caldwell, G.E.; Dunbar, M.J. Biomechanical Changes at the Hip, Knee, and Ankle Joints during Gait Are Associated with Knee Osteoarthritis Severity. J Orthop Res 2008, 26, 332-341, doi:10.1002/jor.20496. 63. Gök, H.; Ergin, S.; Yavuzer, G. Kinetic and Kinematic Characteristics of Gait in Patients with Medial Knee Arthrosis. Acta Orthop Scand 2002, 73, 647-652, doi:10.1080/000164702321039606.

64. Messier, S.P.; Gutekunst, D.J.; Davis, C.; DeVita, P. Weight Loss Reduces Knee-Joint Loads in Overweight and Obese Older Adults with Knee Osteoarthritis. Arthritis Rheum 2005, 52, 2026-2032, doi:10.1002/art.21139.

65. Kim, K.-B.; Shin, Y.-A. Males with Obesity and Overweight. J Obes Metab Syndr 2020, 29, 18-25, doi:10.7570/jomes20008.

66. Nicolella, D.P.; O’Connor, M.I.; Enoka, R.M.; Boyan, B.D.; Hart, D.A.; Resnick, E.; Berkley, K.J.; Sluka, K.A.; Kwoh, C.K.; Tosi, L.L.; et al. Mechanical Contributors to Sex Differences in Idiopathic Knee Osteoarthritis. Biol sex dif 2012, 3 , 28, doi:10.1186/2042-6410-3-28.

67. Teichtahl, A.J.; Wluka, A.E.; Morris, M.E.; Davis, S.R.; Cicuttini, F.M. The Associations Between the Dominant and Nondominant Peak External Knee Adductor Moments During Gait in Healthy Subjects: Evidence for Symmetry. Archives of Physical Medicine and Rehabilitation 2009, 90, 320-324, doi:10.1016/j.apmr.2008.07.030.

68. Stein, B.P.; Boyer, K.A. Impact of Parity on Biomechanical Risk Factors for Knee OA Initiation. Gait Posture 2021, 84, 287-292, doi:10.1016/j.gaitpost.2020.12.024.

69. Wiedemeijer, M.M.; Otten, E. Effects of High Heeled Shoes on Gait. A Review. Gait E Posture 2018, 61, 423-430, doi:10.1016/j.gaitpost.2018.01.036.

70. Tepla, L.; Prochazkova, M.; Svoboda, Z.; Janura, M. Kinematic Analysis of the Gait in Professional Ballet Dancers. Acta Gymnica 2014, 44, 85-91, doi:10.5507/ag.2014.009. 
71. Astephen Wilson, J.L.; Dunbar, M.J.; Hubley-Kozey, C.L. Knee Joint Biomechanics and Neuromuscular Control during Gait before and after Total Knee Arthroplasty Are Sex-Specific. J Arthroplasty 2015, 30, 118-125, doi:10.1016/j.arth.2014.07.028.

72. Phinyomark, A.; Osis, S.T.; Hettinga, B.A.; Kobsar, D.; Ferber, R. Gender Differences in Gait Kinematics for Patients with Knee Osteoarthritis. BMC Musculoskeletal Disorders 2016, 17, 157, doi:10.1186/s12891-016-1013-z.

73. Gregoire, L.; Veeger, H.E.; Huijing, P.A.; van Ingen Schenau, G.J. Role of Mono- and Biarticular Muscles in Explosive Movements. Int J Sports Med 1984, 5, 301-305, doi:10.1055/s-2008-1025921.

74. Cleather, D.J.; Southgate, D.F.L.; Bull, A.M.J. The Role of the Biarticular Hamstrings and Gastrocnemius Muscles in Closed Chain Lower Limb Extension. J Theor Biol 2015, 365, 217-225, doi:10.1016/j.jtbi.2014.10.020.

75. Henriksen, M.; Graven-Nielsen, T.; Aaboe, J.; Andriacchi, T.P.; Bliddal, H. Gait Changes in Patients with Knee Osteoarthritis Are Replicated by Experimental Knee Pain. Arthritis Care Res (Hoboken) 2010, 62, 501-509, doi:10.1002/acr.20033. 